\title{
Analisis Faktor-Faktor yang Mempengaruhi Tingkat Kemiskinan Di Kecamatan Insana Kabupaten Timor Tengah Utara (TTU)
}

\author{
Frederic W. Nalle, \\ Emilia K. Kiha, \\ Fakultas Ekonomi dan Bisnis, Universitas Timor, Kefamenanu, TTU - NTT, Indonesia
}

\begin{abstract}
This study aims to determine whether there is an influence of outpouring hours of work, education. age and number of family cries on the income level of the poor in Insana Subdistrict, Timor Tengah Utara Regency, which was held from May to October 2018. The population in this study was all the poorly-insured people of Insana and the sample technique used was simple random sampling. by using the Slovin formula so that the number of samples is 96 respondents. The data analysis technique used is Multiple Linear Regression Analysis with hypothesis testing t test and F test.

The results showed that both partially and simultaneously there were positive and significant influences between working hours (X1), education (X2), age (X3), and the number of family dependents (X4) on income (Y) Insana District Poor Community Timor Tengah Utara. This result is seen from the regression regression coefficient that is positive and also the comparison of the calculated $t$ value greater than $t$ table and the calculated $F$ value greater than $\mathrm{F}$ table.
\end{abstract}

Keywords: Exposure to Working Hours, Education, Age, Number of Family Dependents, Income, Poverty

JEL Classification: I21, I32

\section{PENDAHULUAN}

Pembangunan ekonomi di Indonesia saat ini sedang dihadapkan terhadap masalah kemiskinan. Pada umumnya di Negara berkembang seperti Indonesia permasalahan pendapatan yang rendah dengan masalah kemiskinan merupakan permasalahan utama dalam pembangunan ekonomi. Dengan demikian dalam tujuan ekonomi kedua masalah tersebut dinyatakan bersamaan sehingga menjadi satu kalimat yaitu peningkatan pendapatan nasional dan pengurangan kemiskinan (Suharjo,1997).

Kemiskinan merupakan hal klasik yang belum tuntas terselesaikan terutama di Negara berkembang, artinya kemiskinan menjadi masalah yang dihadapi dan menjadi perhatian di setiap Negara. Persoalan kemiskinan merupakan salah satu permasalahan pokok yang dihadapi bangsa Indonesia sejak dahulu hingga sekarang. Berbagai perencanaan, kebijakan serta program pembangunan yang telah dan akan dilaksanakan pada intinya adalah mengurangi jumlah penduduk miskin. Permasalahan kemiskinan merupakan permasalahan yang kompleks dan multidimensional. Upaya pengentasan dan pengurangan kemiskinan harus dilakukan secara komperhensif, mencakup seluruh aspek hidupan dan dilaksanakan secara terpadu. Kemiskinan terjadi karena kemampuan masyarakat pelaku ekonomi tidak sama, sehingga terdapat masyarakat yang tidak dapat ikut serta dalam proses pembangunan atau menikmati hasil pembangunan (Soegijoko, 2001). 
Perhatian pemerintah Indonesia terhadap kemiskinan dituangkan didalam Rencana Pembangunan Jangka Menengah Nasional (RPJMN) 2015-2019. Penurunan jumlah kemiskinan hingga 10,86 persen pada tahun 2016 merupakan salah satu sasaran pertama dalam hal agenda pemerintah meningkatkan kesejahteraan rakyat yang dapat dilihat pada tabel 1.1 dbawah ini. Bahkan untuk mencapai sasaran tersebut pemerintah merumuskan prioritas pembangunan nasional 2015-2019 adalah penanggulangan kemiskinan dengan kebijakan yang diarahkan untuk menghormati, melindungi, dan memenuhi hak-hak dasar masyarakat miskin.

Di era pemerintahan Susilo Bambang Yudhoyono, menegaskan kepeduliannya untuk mengatasi pengangguran dan kemiskinan tersebut kemudian dirumuskan dengan new deal dalam pembangunan ekonomi Indonesia. Ringkasan dari new deal tersebut tertuang dalam prinsip triple track strategy: progrowth, pro-job, dan pro-poor. Track pertama dilakukan dengan meningkatkan pertumbuhan dengan mengutamakan ekspor dan investasi. Track kedua, menggerakan sektor riil untuk menciptakan lapangan pekerjaan. Dan yang ketiga, revitilisasi pertanian, kehutanan, kelautan dan ekonomi pedesaan untuk mengurangi kemiskinan.

Sejak digiatkan kembali program-program pengentasan kemiskinan tersebut, jumlah penduduk miskin (penduduk dengan pengeluaran per kapita per bulan di bawah garis kemiskinan) secara perlahan berhasil diturunkan jumlahnya. Jumlah penduduk miskin di Indonesia pada bulan September 2016 sebesar 28,01 juta jiwa (11,96 persen). Dibandingkan penduduk miskin pada bulan 2012 besar 29,13 juta orang (13,33 persen ), berarti jumlah penduduk miskin turun besar 1,12 juta orang (Susenas, 2016).

Tabel 1

Jumlah Penduduk Miskin di Indonesia

Tahun 2012-2016 (dalam juta jiwa)

\begin{tabular}{|c|c|}
\hline Tahun & Jumlah penduduk miskin \\
\hline 2012 & $29.13(11,96 \%)$ \\
\hline 2013 & $28.07(11,37 \%)$ \\
\hline 2014 & $28.28(11,25 \%)$ \\
\hline 2015 & $28.59(11,22 \%)$ \\
\hline 2016 & $28.01(10,86 \%)$ \\
\hline
\end{tabular}

Provinsi Nusa Tenggara Timur (NTT) merupakan salah satu contoh daerah yang masih menghadapi permasalahan kemiskinan dan penanggulangan kemiskinan. Masih tingginya angka kemiskinan disetiap Kabupaten/Kota di Provinsi NTT, membuat provinsi ini terus dilanda permasalahan kemiskinan. Tabel 1 menunjukan tingkat rata-rata kemiskinan di Indonesia (34 Provinsi). Dalam perbandingan rata- rata tingkat kemiskinan di seluruh provinsi di Indonesia tahun 2016 periode Maret dan September, provinsi NTT memiliki rata-rata kemiskinan 22,19 dan 22,01 persen dimana NTT menduduki peringkat ke tiga provinsi termiskin setelah Papua dan Papua Barat.

Kondisi sebagian besar alam di Provinsi Nusa Tenggara Timur tandus dan gersang. Kekeringan dan rawan pangan seolah menjadi bencana rutin yang dihadapi warga NTT hampir setiap tahun. Kemiskinan, kasus gizi buruk, angka putus sekolah, serta akses fasilitas kesehatan yang kurang memadai pada akhirnya menjadi mata rantai lanjutan dari persoalan itu. Sumber Daya Alam (SDA) yang cukup besar dan beragam yang tersebar di setiap daerah, namun sampai saat ini potensi setiap sektor tersebut belum secara optimal dapat memberikan nilai tambah yang signifikan untuk mensejahterakan rakyat dan daerah NTT. Hal ini sebabkan karena masih kurangnya investasi yang dilakukan. Perkembangan angka kemiskinan di Nusa Tenggara Timur Kondisi ini menyebabkan berbagai persoalan di daerah itu mulai dari masalah kesehatan, kualitas sumber daya manusia, pengangguran dan persoalan sosial lainnya. 
Tabel2

\begin{tabular}{|c|c|c|c|c|c|c|c|}
\hline \multicolumn{8}{|c|}{ Persentase Jumlah Penduduk Miskin antar Provinsi di Indonesia } \\
\hline No & PROVINSI & MARET & SEPT & No & PROVINSI & MARET & SEPT \\
\hline 1 & PAPUA & 28.54 & 28.40 & 18 & SULAWESI SELATAN & 9.40 & 9.24 \\
\hline 2 & PAPUA BARAT & 25.43 & 24.88 & 19 & JAWA BARAT & 8.95 & 8.77 \\
\hline 3 & NUSA TENGGARA TIMUR & 22.19 & 22.01 & 20 & JAMBI & 8.41 & 8.37 \\
\hline 4 & MALUKU & 19.18 & 19.26 & 21 & SULAWESI UTARA & 8.34 & 8.20 \\
\hline 5 & GORONTALO & 17.72 & 17.63 & 22 & KALIMANTANBARAT & 7.87 & 8 \\
\hline 6 & BENGKULU & 17.32 & 17.03 & 23 & RIAU & 7.98 & 7.67 \\
\hline 7 & $\mathrm{ACEH}$ & 16.73 & 16.43 & 24 & SUMATERA BARAT & 7.09 & 7.14 \\
\hline 8 & NUSA TENGGARA BARAT & 16.48 & 16.02 & 25 & KALIMANTANUTARA & 6.23 & 6.99 \\
\hline 9 & SULAWESI TENGAH & 14.45 & 14.09 & 26 & MALUKUUTARA & 6.33 & 6.41 \\
\hline 10 & LAMPUNG & 14.29 & 13.86 & 27 & KALIMANTAN TIMUR & 6.11 & 6 \\
\hline 11 & SUMATERA SELATAN & 13.54 & 13.39 & 28 & KEP.RIAU & 5.98 & 5.84 \\
\hline 12 & JAWA TENGAH & 13.27 & 13.19 & 29 & KALIMANTAN TENGAH & 5.66 & 5.36 \\
\hline 13 & DI YOGYAKARTA & 13.34 & 13.10 & 30 & BANTEN & 5.42 & 5.36 \\
\hline 14 & SULAWESI TENGGARA & 12.88 & 12.77 & 31 & KEP. BANGKA BELITUNG & 5.22 & 5.04 \\
\hline 15 & JAWA TMMUR & 12.05 & 11.85 & 32 & KALIMANTAN SELATAN & 4.85 & 4.52 \\
\hline 16 & SULAWESI BARAT & 11.74 & 11.19 & 33 & BALI & 4.25 & 4.15 \\
\hline 17 & SUMATERA UTARA & 10.35 & 10.27 & 34 & DKI JAKARTA & 3.75 & 3.75 \\
\hline
\end{tabular}

Perkembangan angka kemiskinan di Nusa Tenggara Timur (NTT) mencerminkan beratnya beban pemerintah dalam pengentasan kemiskinan penduduknya. Dari Tabel 2 diperoleh bahwa Kabupaten yang memiliki jumlah penduduk miskin tertinggi di provinsi NTT yaitu Kabupaten Timor Tengah Selatan (TTS) dengan jumlah penduduk miskin tahun 2015 sebanyak 144,01 ribu jiwa (31,35 persen) dari total penduduk 459.310 jiwa. Tingginya tingkat kemiskinan di Kabupaten Timor Tengah Selatan dikarenakan, secara topografis wilayah kabupaten TTS memiliki curah hujan yang rendah sehingga lahan di wilayah tersebut umumnya kering dan tandus, selain itu sektor pertanian (95,3 persen) masih memegang peranan penting karena sebagian besar penduduk bekerja dan mengandalkan hidupnya dari pertanian (Amelia, 2012).

Sedangkan Timor Tengah Utara yang berdekatan dengan TTS berada pada urutan ke delapan dengan jumlah penduduk miskin sebesar 61,96 ribu jiwa atau 22,18 persen, dimana masyarakat Kabupaten Timor Tengah Utara (TTU) sebagian besar bermukim di pedesaan yang senantiasa mengandalkan sektor pertanian sebagai sumber utama untuk memenuhi kebutuhan hidupnya. Untuk itu, perhatian pembangunan perlu diarahkan kepada pembangunan pedesaan. Hal ini dilakukan karena masyarakat di pedesaan masih diliputi dengan masalah kemiskinan, keterbelakangan dan berbagai kerawanan sosial lainnya.

Tabel 3

Jumlah Penduduk Miskin di Nusa Tenggara Timur Tahun 2015 (dalam ribu jiwa)

\begin{tabular}{|r|l|r|r|l|r|}
\hline No & Kabupten/Kota & Jumlah & No & Kabupten/Kota & Jumlah \\
\hline 1 & Timor Tengah Selatan & 144.01 & 12 & Sikka & 44.64 \\
\hline 2 & Sumba Barat Daya & 96.54 & 13 & Kota Kupang & 39.73 \\
\hline 3 & Kupang & 80.98 & 14 & Sumba Barat & 37.35 \\
\hline 4 & Sumba Timur & 77.95 & 15 & Lembata & 35.93 \\
\hline 5 & Manggarai Timur & 77.67 & 16 & Belu & 34.75 \\
\hline 6 & Manggarai & 74.01 & 17 & Malaka & 32.28 \\
\hline 7 & Ende & 63.23 & 18 & Sabu Raijua & 28.43 \\
\hline 8 & Timor Tengah Utara & 61.96 & 19 & Sumba Tengah & 24.69 \\
\hline 9 & Manggarai Barat & 50.98 & 20 & Flores Timur & 24.02 \\
\hline 10 & Alor & 45.83 & 21 & Nagekeo & 20 \\
\hline 11 & Rote Ndao & 45.01 & 22 & Ngada & 19.85 \\
\hline
\end{tabular}

Sumber: BPS Nusa Tenggaara Timur 2016

Penyelenggaraan pembangunan di Kabupaten Timor Tengah Utara diperhadapkan pada beberapan permasalahan, sebagai berikut: Pertama, Tingginya angka kemiskinan. Dalam Penyelarasan RPJMD TTU Tahun 2011-2015 disebutkan bahwa jumlah penduduk miskin di Kabupaten TTU menurut Data Terpadu PPLS tahun 2011 adalah 31.175 KK atau sebesar 55,54\% dari 56. 494 KK. Tahun 2012, data 
BPS menunjukkan bahwa jumlah penduduk miskin di Kabupaten Timor Tengah Utara: 51.200 jiwa atau $25.600 \mathrm{KK}$ atau 44,47 \%. Kedua, Rendahnya kualitas sumber daya manusia. Kemiskinan berimplikasi pada rendahnya kualitas sumber daya manusia di Kabupaten TTU karena dengan kondisi tersebut masyarakat tidak mampu memperoleh pendidikan formal yang baik sehinggga SDM masyarakat masih rendah dan kondisi kesehatan masyarakat yang buruk. Ketiga, Masalah rawan bencana alam. Wilayah Kabupaten TTU sering dilanda bencana alam seperti banjir, tanah longsor dan kekeringan yang mengakibatkan kerusakan pada lahan pertanian masyarakat.

Mengacu pada Rekapitulasi Kecamatan dan Desa yang Mengalami Rawan Pangan tahun 2010 menunjukkan bahwa di Kabupaten Timor Tengah Utara terdapat 15 Kecamatan, 64 Desa, 12.679 Kepala Keluarga dan 63.395 jiwa mengalami resiko rawan pangan (Tiza, 2014)

\begin{tabular}{|c|c|c|c|c|c|c|c|c|c|}
\hline \multicolumn{10}{|c|}{$\begin{array}{l}\text { Jumlah Penduduk Miskin antar Kecamatan/Kota } \\
\text { di Timor Tengah Utara (TTU) Tahun } 2017\end{array}$} \\
\hline \multirow{2}{*}{$\begin{array}{l}\mathrm{N} \\
0\end{array}$} & \multirow{2}{*}{ KECAMATAN } & \multicolumn{3}{|c|}{ JMLAH } & \multirow{2}{*}{ No } & \multirow{2}{*}{ KECAMATAN } & \multicolumn{3}{|c|}{ JUMLAH } \\
\hline & & DESA & $\mathrm{KK}$ & תWA & & & DESA & $\mathrm{KK}$ & JWA \\
\hline 1 & INSANA & 17 & 2.993 & 12.045 & 13 & MUTIS & 4 & 1.293 & 5.168 \\
\hline 2 & BIBOKI UTARA & 9 & 2.149 & 9.306 & 14 & INSANA BARAT & 12 & 1.076 & 4.910 \\
\hline 3 & BIBOKI ANLEU & 9 & 1.979 & 9.262 & 15 & BIBOKI MOENLEU & 7 & 976 & 4.473 \\
\hline 4 & MIOMAFFO BARAT & 13 & 2.470 & 9.081 & 16 & INSANA FAFINESU & 6 & 1.079 & 4.273 \\
\hline 5 & BIKOMI SELATAN & 10 & 1.544 & 5.967 & 17 & $\begin{array}{l}\text { MIOMAFFO } \\
\text { TENGAH }\end{array}$ & 6 & 1.065 & 4.123 \\
\hline 6 & BIBOKI UTARA & 10 & 1.326 & 5.912 & 18 & BIBOKI TANPAH & 4 & 907 & 3.580 \\
\hline 7 & INSANA TENGAH & 7 & 1.288 & 5.621 & 19 & MUSI & 6 & 973 & 3.523 \\
\hline 8 & MIOMAFFO TIMUR & 11 & 1.444 & 5.595 & 20 & BIKOMIUTARA & 9 & 924 & 3.496 \\
\hline 9 & INSANA UTARA & 5 & 1.251 & 5.586 & 21 & BIBOKI FEOTLEU & 5 & 644 & 3.020 \\
\hline 10 & BIKOMI TENGAH & 9 & 1.445 & 5.441 & 22 & NAIBENU & 4 & 647 & 2.908 \\
\hline 11 & NOEMUTI & 12 & 1.328 & 5.254 & 23 & BIKOMINILULAT & 6 & 773 & 2.841 \\
\hline 12 & BIBOKI SELATAN & 8 & 1.300 & 5.189 & 24 & NOEMUTI TIMUR & 4 & 509 & 1.780 \\
\hline
\end{tabular}

Dari tabel 4 Jumlah Penduduk Miskin antar Kecamatan/Kota di Timor Tengah Utara (TTU) Tahun 2017 dapat dilihat bahwa jumlah penduduk miskin terbanyak di Kecamatan Insana sebesar 2.993 KK atau 12.045 jiwa yang tersebar di 17 desa kemudian kedua di duduki oleh Kecamatan Biboki Utara sebesar 2.149 KK atau 9.309 jiwa yang tersebar di 9 desa, sedangkan jumlah penduduk miskin terendah berada di kecamatan Noemuti Timur dengan jumlah penduduk miskin sebesar 509 KK atau 1.780 jiwa yang tersebar di 4 desa.

Kecamatan Insana merupakan salah satu kecamatan di Kabupaten Timor Tengah Utara (TTU). Umumnya kecamatan kota adalah kecamatan yang letaknya secara geografis paling dekat dengan pusat pemerintahan memiliki tingkat pendapatan yang lebih tinggi jika dibandingkan dengan kecamatankecamatan lain, tetapi di Kecamatan Kota ini jumlah penduduk miskin justru menempati urutan kedua dari dua puluh empat Kecamatan di Kabupaten Timor Tengah Utara (TTU). Pemerintah harus melakukan upaya-upaya untuk mengatasi kemiskinan yang terjadi, diantaranya memperluas lapangan kerja, memperbaiki layanan publik seperti pendidikan dan kesehatan. Hal yang sudah dilakukan pemerintah adalah melakukan program pengentasan kemiskinan adalah dengan membuat program Bantuan Langsung Tunai (BLT) yang akan diberikan pada tiap-tiap keluarga miskin tiap bulannya. Namun upaya tersebut belum sepenuhnya mengurangi kemiskinan di Kecamatan Kota Kabupaten Timor Tengah Utara (TTU).

Berdasarkan hal diatas maka peneliti tertarik untuk meneliti tentang "Faktor-Faktor Yang Mempengaruhi Tingkat Kemiskinan di Kecamatan Insana Kabupaten Timor Tengah Utara (TTU)".

Penelitian ini bertujuan untuk mengetahui (1) Pengaruh curahan jam kerja terhadap penghasilan keluarga miskin di Kecamatan Insana Kabupaten Timor Tengah Utara (TTU) ; (2) Pengaruh pendidikan terhadap penghasilan keluarga miskin di Kecamatan Insana Kabupaten Timor Tengah Utara (TTU) ; (3) Pengaruh usia terhadap penghasilan keluarga miskin di Kecamatan Insana Kabupaten Timor Tengah Utara (TTU) ; (4) Pengaruh jumlah tanggungan keluarga terhadap penghasilan keluarga miskin di Kecamatan Insana Kabupaten Timor Tengah Utara (TTU). 


\section{LANDASAN TEORI}

Kemiskinan merupakan dimana seseorang hidup dibawah standar kebutuhan minimum yang telah ditetapkan berdasarkan kebutuhan pokok pangan yang membuat seseorang cukup untuk bekerja dan hidup sehat berdasarkan kebutuhan beras dan gizi (Sajogyo). Seseorang dikatakan miskin apabila tidak memperoleh penghasilan setara dengan 320 kilogram beras untuk daerah pedesaan, dan 480 kilogram beras untuk masyarakat yang tinggal di daerah perkotaan (Sajogyo).

Menurut Sharp et al. (2000), kemiskinan terjadi dikarenakan beberapa sebab yaitu: rendahnya kualitas angkatan kerja, akses yang sulit terhadap kepemilikan modal, rendahnya penguasaan teknologi, penggunaan sumberdaya yang tidak efisien dan tinggginya pertumbuhan penduduk. Sedangkan menurut Kuncoro (2000) kemiskinan dapat disebabkan oleh : a) Kemiskinan muncul akibat perbedaan akses dan modal; b) Kemiskinan muncul akibat rendahnya kualitas sumber daya manusia sehingga akan mempengaruhi terhadap produktifitas dan pendapatan yang diperoleh. Jika dilihat secara makro maka kemiskinan muncul akibat ketidaksamaan pola kepemilikan sumber daya sehingga akan menyebabkan distribusi pendapatan yang timpang.

Dari beberapa teori yang diuraikan di atas maka melahirkan beberapa variabel dalam penelitian ini, yang antara lain adalah :

1. Curahan Jam Kerja

Curahan jam kerja kerja adalah jumlah jam kerja yang dihabiskan oleh seseorang untuk melakukan kegiatan bekerja. Dengan kegiatan bekerja seseorang dapat memperoleh upah atau penghasilan. Jumlah curahan jam kerja setiap seseorang bekerja tidaklah sama, ada yang bekerja paruh waktu dan ada yang juga bekerja penuh sesuai dengan keinginan sendiri. Oleh karena itu dalam menyediakan waktu untuk bekerja tidak cukup hanya memperhatikan dari jumlah jam kerja per hari tetapi perlu juga diperhatikan dalam setiap minggunya (Sumarsono, 2002:54).

2. Pendidikan

Pendidikan adalah suatu proses dimana terjadi perubahan sikap, perilaku maupun kebiasaan yang buruk yang dimiliki seseorang menjadi lebih baik melalui proses pengajaran. Dengan proses pengajaran tersebut diharapkan mampu mencetak sumber daya manusia yang unggul dan mampu bersaing dalam dunia kompetensi kerja yang dikenal cukup sulit. Menurut Riberu (1993:29) bahwa dengan proses pendidikan manusia (masyarakat) akan dapat berfikir secara rasional dan logis. Dengan berpikir secara rasional maka akan dapat menjadi dasar pijakan untuk memandang dan menyelesaikan permasalahan.

3. Usia

Tingkat usia merupakan salah satu indikator penentu produktifitas kerja seseorang. Hal ini dapat terlihat seseorang yang berusia produktif antara usia 17-50 tahun mampu berproduktifitas dengan baik dan menghasilkan sesuatu yang berguna dikarnakan usia mereka masih muda dan memiliki fisik yang masih kuat jika dibandingkan dengan seseorang yang sudah memasuki usia tidak produktif $\geq 50$ tahun. Dengan tidak produktifitas kemampuan manusia maka akan jelas mempengaruhi jumlah curahan jam kerja dan jumlah penghasilan yang didapatkan dikarnakan faktor tingkat usia yang dimiliki.

4. Jumlah tanggungan keluarga

Jumlah tanggungan keluarga adalah mereka yang menjadi tanggungan kepala keluarga baik itu adik, anak, suami dan lainnya. Rumah tangga dengan jumalh tanggungan anggota keluarga lebih banyak tentu akan melakukan konsumsi lebih besar, sehingga mereka tidak dapat mencukupi kebutuhan sekundernya. Jika kebutuhan sekundernya ingin terpenuhi mereka harus mendapatkan penghasilan yang lebih besar. Sulitnya lapangan pekerjaan dan rendahnya pendapatan menyebabkan seseorang lebih berat dalam meningkatkan kesejahteraan hidupnya, apalagi jika ditambah dengan banyaknya anggota keluarga yang ditanggungnya. (Zainullah, 2015). 


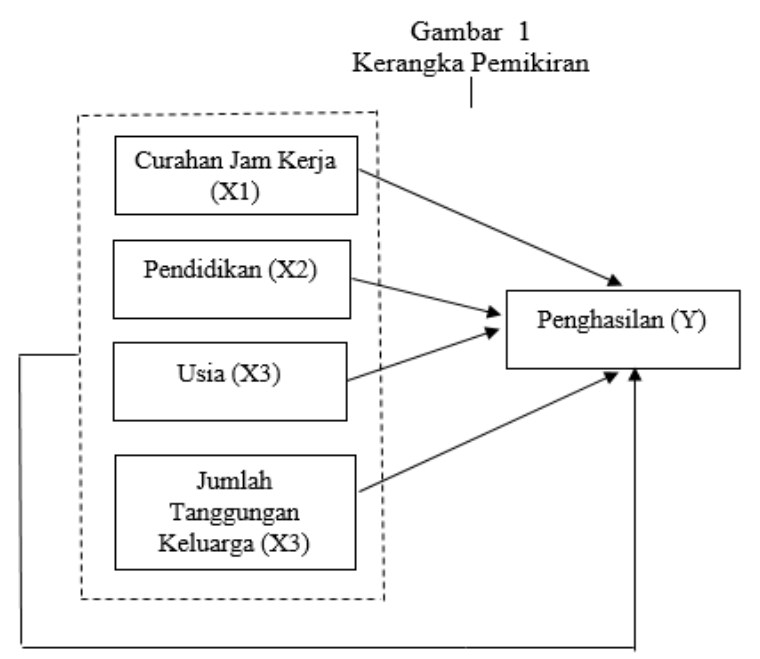

\section{METODE}

Penelitian ini akan dilakukan pada bulan mei sampai dengan oktober 2018 di Kecamatan Insana Kabupaten Timor Tengah Utara, Provinsi NTT. Populasi dalam penelitian ini meliputi seluruh masyarakat desa yang tergolong miskin yang berada di Kecamatan Insana yang keseluruhan berjumlah 2.149 responden. Proses penentuan jumlah sampel dengan mengunakan metode yang disampaikan oleh Slovin dalam Riduwan (2007) diperoleh 96 orang sebagai responden.

Sumber data dalam penelitian ini adalah data primer dan data sekunder. Data primer diperoleh dari masyarakat miskin di Kecamatan Insana sedangkan data sekunder berasal dari dokumen-dokumen pendukung seperti Badan Pusat Statistik (BPS) Kabupaten Timor Tengah Utara, Kantor Kecamatan Insana dan juga Kantor Desa. Teknik pengumpulan data dengan melakukan observasi secara langsung dengan mengamati bagaimana kegiatan masyarakat dalam menjalankan kegiatan usaha tani, wawancara secara terbuka dan tertutup dengan menggunakan koesioner atau daftar pertanyaan yang disediakan sebelumnya baik kepada responden maupun kepada Aparatur Pemerintah di tingkat Kecamatan dan juga Desa.

Alat analisis yang digunakan dalam penelitian ini adalah analisis regresi linear berganda, dimana untuk menjawab permasalahan penelitian yaitu ; untuk mengetahui pengaruh curahan jam kerja, tingkat pendidikan, usia dan jumlah tanggungan keluarga terhadap tingkat kemiskinan di Kecamatan Insana Kabupaten Timor Tengah Utara (TTU), digunakan analisis regresi linier berganda menurut Supranto (2001:189) :

\section{$\mathrm{Y}=\mathrm{b} 0+\mathrm{b} 1 \mathrm{X} 1+\mathrm{b} 2 \mathrm{X} 2+\mathrm{b3X} 3+\mathrm{b} 4 \mathrm{X} 4+\mathrm{e}$}

Sebelum data di analisis, maka dalam analisis regresi berganda hal yang pertama dilakukan adalah dilakukannya uji asumsi klasik. Ada beberapa tahapan pengujian asumsi klasik yang antara lain adalah uji normalitas, uji multikolineaaritas, uji autokorelasi dan uji heteroskesdastisitas.

\section{HASIL DAN PEMBAHASAN}

\subsection{Uji Asumsi Kllasik}

\section{a. Uji Normalitas}

Dalam penelitian ini uji normalitas pada model regresi digunakan untuk menguji apakah nilai residual yang dihasilkan dari regresi terdistribusi secara normal atau tidak. Model regresi yang baik adalah yang memiliki nilai residual yang terdistribusi secara normal. Beberapa metode uji normalitas yaitu dengan melihat penyebaran data pada sumbu diagonal pada grafik Normal $P-P$ Plot of regression standardized residual dan juga bisa dilakukan dengan uji One Sample Kolmogorof. Namun dalam penelitian ini peneliti hanya menggunakan metode Normal P-P Plot of regression standardized residual.

Dengan melihat penyebaran data pada hasil olahan data yang tersaji dalam gambar diagram Normal P-P Plot of Regression Standardized Residual, jika nilai residual menyebar secara teratur mengikuti sumbu diagonal maka dapat dismpulkan bahwa data penelitian telah berdistribusi normal. 
Berikut ini disajaikan gambar diagram Normal P-P Plot of Regression Standardized Residual.

Gambar 2

Diagram Uji Normalitas

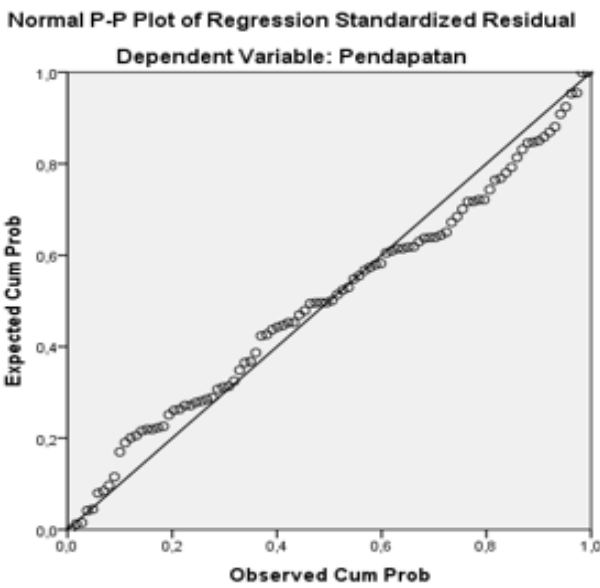

Sumber : Hasil Olahan Data Primer Tahun 2018

\section{b. Uji Multikolinearitas}

Multikoliniaritas adalah keadaan dimana pada model regresi ditemukan adanya korelasi yang sempurna atau mendekati sempurna antar variable independen. Pada model regresi yang baik, seharusnya tidak terjadi korelasi yang sempurna di antara variable bebas. Metode Uji Multikolonearitas yaitu dengan melihat nilai Tolerance dan Invlation Faktor (VIF) pada model regresi. Apabila nilai tolerance $>0,1$ dan nilai VIF $<10$ maka tidak terdapat gejala Multikolinearitas. Sebaliknya apabila nilai tolerance $<0,1$ dan nilai VIF $>10$ maka terdapat gejala multikolinearitas dalam model regresi.

Tabel 5

Hasil Uji Multikolinearitas

\begin{tabular}{|c|c|}
\hline \multicolumn{2}{|c|}{ Nilai Coeificient } \\
\hline Tolenrance & VIF \\
\hline 0,236 & 4,232 \\
\hline 0,275 & 3,630 \\
\hline 0,310 & 3,229 \\
\hline 0,183 & 5,464 \\
\hline
\end{tabular}

Sumber :Hasil analisis olahan data primer dengan SPSS 22,0

Dari tabel Output Coefficient diatas dapat diketahui bahwa nilai Tolerance ketiga variable lebih dari 0,1 dan nilai VIF kurang dari 10 maka dapat disimpulkan bahwa tidak terdapat gejala multikolinearitas.

\section{c. Uji Autokorelasi}

Autokorelasi adalah keadaan dimana pada model regresi ada korelasi antara residual pada periode $\mathrm{t}$ dengan residual pada periode sebelumnya ( $\mathrm{t}-1)$. Model regresi yang baik adalah yang tidak terdapat masalah autokorelasi. Metode pengujian menggunakan Uji Durbin Watson (DW test). Pengambilan keputusan pada uji Durbin Watson adalah sebagai berikut :

Jika nilai DU $<$ DW $<4$-DL maka tidak terjadi gejala autokorelasi.

Jika nilai DU $<$ DL atau nilai DW $>4-$ DL, artinya terjadi gejala autokorelasi.

Nilai DU dan DL ini dapat diperoleh dari tabel statistik Durbin Watson (Priyatno, 2013). Dari hasil perhitungan dengan menggunakan bantuan SPSS 22 for windows diperoleh hasil dalam tabel dibawah ini. 
Tabel 5

Hasil Uii Autokorelasi

\begin{tabular}{|l|r|r|r|r|r|}
\hline Model & $R$ & $R$ Square & $\begin{array}{c}\text { Adjusted R } \\
\text { Square }\end{array}$ & $\begin{array}{c}\text { Std. Error of the } \\
\text { Estimate }\end{array}$ & Durbin-Watson \\
\hline 1 & $.958^{\mathrm{a}}$ & .918 & .914 & 326567.953 & 1,784 \\
\hline
\end{tabular}

a. Predictors: (Constant), Jh Tangg Kel., Pendidikan, Usia, Jam Kerja

b. Dependent Variable: Pendapatan

Sumber: Hasil olahan data primer menggunakan program SPSS 22,0

Dari output diatas diperoleh nilai Durbin Watson sebesar 1,784 sedangkan nilai DU dan DL yang diperoleh dari tabel Durbin Watson dengan $\mathrm{n}($ sampel $)=96$ dan $\mathrm{k}$ (variabel bebas $=4)$ didapat nilai $\mathrm{DL}=1,5821$ dan DU $=1,7553$. Jadi nilai DL sebesar 1,5821 dan besaran nilai $4-$ DL atau 4 $-1,5821$ = 2,4179 (Tabel Durbin Watson terlampir).

Dari hasil perhitungan di atas maka dapat ditarik kesimpulan bahwa karena nilai DW $(1,784)$ terletak diantara nilai DU $(1,7553)$ dan nilai 4-DL $(2,4179)$ atau $1,5821<1,7553<2,4179$ maka tidak ada gejala autokorelasi pada model regresi.

\section{d. Uji Heteroskesdastisitas}

Heteroskedastisitas adalah keadaan dimana dalam model regresi terjadi ketidaksamaan varian dari residual pada satu pengamatan ke pengamatan yang lain. Model regresi yang baik adalah tidak terjadi Heteroskedastisitas. Ada dua (2) macam cara dalam menguji heterokedastisitas, yaitu ; dengan Uji Glejser, dimana dalam bentuk pengujian ini dengan melihat pola titik-titik pada scatterplots regresi. Jika penyebarannya titik-titik tersebut tidak membentuk pola yang jelas dan titik-titik tersebut menyebar di atas dan di bawah angka nol (0) pada sumbu Y maka dapat disimpulkan tidak terjadi masalah Heteroskedastisitas. Begitu juga sebaliknya, jika penyebaran titik-titik terdapat pola yang jelas di atas atau di bawah angka nol (0) pada sumbu Y maka terdapat masalah heteroskedastisitas (Priyatno, 2013).

Selain itu pengujian Heteroskedastisitas juga bisa dilakukan dengan cara menguji koefisien korelasi Spearman's rho dengan menggunakan nilai signifikansi sebesar 0,05. Akan tetapi dalam penelitian ini, peneliti hanya menggunakan teknik pengujian dengan menggunakan Uji Glesjer.

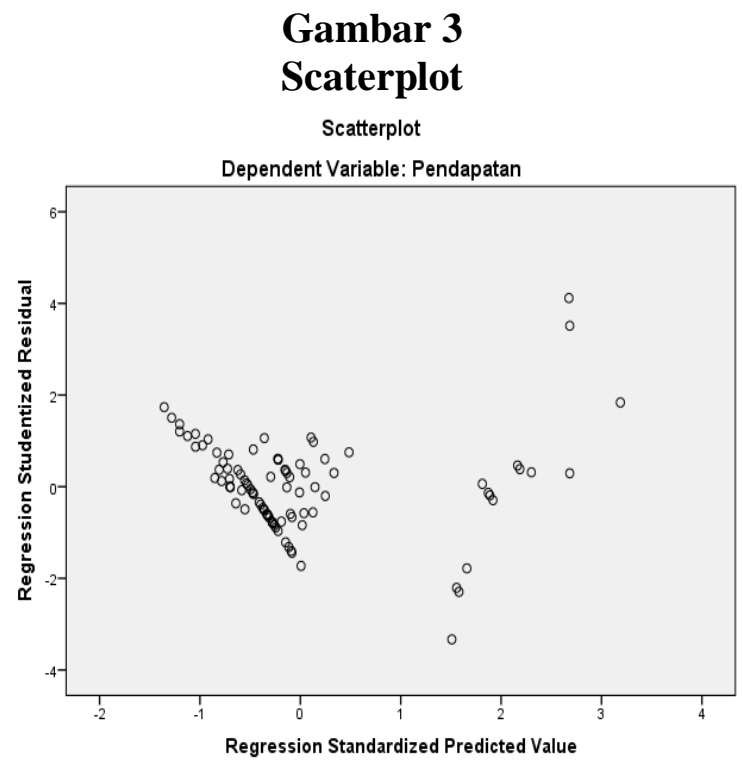

Sumber : Hasil Olahan Data Primer Tahun 2018

Dari hasil analisis dengan bantuan program SPPS 22,0 for windows dapat dilihat bahwa penyebaran titik-titik residual tidak teratur (tidak membentuk suatu pola tertentu) maka kesimpulan yang bisa diambil bahwa tidak terjadi gejala Homokedastisitas (gejala varians residual yang sama antar pengamatan) sehingga asumsi ini terpenuhi. 


\subsection{Hasil Analisis Inferensial}

Berdasarkan hasil analisis data dengan menggunakan bantuan program SPSS 22 diperoleh nilai koefisen determinan ( $R$ Square) sebesar 0,918, yang artinya kontribusi sumbangan pengaruh masingmasing variabel bebas (curahan jam kerja, pendidikan, usia dan jumlah tanggungan keluarga) terhadap variabel terikat (pendapatan) sebesar 91,8\% sedangkan sisanya sebesar 8,2\% dipengaruhi oleh variabel lain yang tidak dimasukan dalam penelitian ini.

Selanjutnya dari hasil analisis data pada tabel coeficient diperoleh persamaan regresi linear berganda

\section{$Y=2627927,316+92412,585 X_{1}+21071,230 X_{2}+16807,292 X_{3}+17024,149 X_{4}$}

Dari olahan data penelitian regresi linear berganda yang tertera dalam persamaan diatas maka dapat dijelaskan:

a. Nilai $\beta 0=2627927,316$; artinya jika tidak ada perubahan pada variabel curahan jam kerja $\left(\mathrm{X}_{1}\right)$, pendidikan $\left(\mathrm{X}_{2}\right)$, usia $\left(\mathrm{X}_{3}\right)$ dan variabel jumlah tanggungan keluarga $\left(\mathrm{X}_{4}\right)$ maka pendapatan masyarakat (Y) di Kecamatan Insana Kabupaten TTU sebesar Rp. 2627927,316.

b. Nilai koefisien regresi variable curahan jam kerja ( $\beta 1)$ bernilai positif sebesar 92412,585. Artinya bahwa: setiap peningkatan jam kerja $\left(\mathrm{X}_{1}\right)$ sebesar 1 jam maka pendapatan masyarakat $(\mathrm{Y})$ juga akan mengalami peningkatan sebesar Rp. 92412,585 dengan asumsi nilai variable independent lainnya tetap.

c. Nilai koefisien regresi variable pendidikan (B2) bernilai positif sebesar 21071,230. Artinya bahwa: setiap peningkatan pendidikan $\left(\mathrm{X}_{2}\right)$ sebesar 1 tahun maka pendapatan masyarakat $(\mathrm{Y})$ juga akan mengalami peningkatan sebesar Rp. 21071,230 dengan asumsi nilai variable independent lainnya tetap.

d. Nilai koefisien regresi variable usia (B3) bernilai positif sebesar 16807,292. Artinya bahwa: setiap peningkatan usia $\left(\mathrm{X}_{3}\right)$ sebesar 1 satuan maka pendapatan masyarakat (Y) juga akan mengalami peningkatan sebesar 16807,292 dengan asumsi nilai variable independent lainnya tetap.

e. Nilai koefisien regresi variable jumlah tanggungan keluaraga ( $\beta 4)$ bernilai positif sebesar 17024,149 . Artinya bahwa: setiap peningkatan jumlah tanggungan keluarga $\left(\mathrm{X}_{4}\right)$ sebesar 1 orang maka pendapatan masyarakat (Y) juga akan mengalami peningkatan sebesar Rp. 17024,149 dengan asumsi nilai variable independent lainnya tetap.

Untuk mengetahui pengaruh variabel curahan jam kerja, pendidikan, usia, dan jumlah tanggungan keluarga terhadap pendapatan masyarakat miskin di Kecamatan Insana Kabupaten Timor Tengah Utara maka diketahui bahwa nilai $\mathrm{F}_{\text {hitung }} 253,195>$ nilai $\mathrm{F}_{\text {tabel }} 2,47$ dan nilai signifikansi sebesar 0,000 $<0,005$. $\mathrm{Hal}$ ini berarti $\mathrm{H0}$ ditolak dan Ha diterima yang menunjukan bahwa secara simultan ada pengaruh yang signifikan variabel curahan jam kerja, pendidikan, usia dan jumlah tanggungan keluarga terhadap pendapatan masyarakat di Kecamatan Insana Kabupaten Timor Tengah Utara.

1) Pengaruh Curahan Jam Kerja $\left(\mathbf{X}_{1}\right)$ Terhadap Pendapatan (Y) Masyarakat Miskin Kecamatan Insana

Dari hasil penelitian dan analisis data diperoleh nilai koefisen regresi positif sebesar 92412,585 serta untuk alpha (a) sebesar $0,05 \mathrm{dan} \mathrm{dk}=\mathrm{n}-\mathrm{k}(96-4=92)$ memperoleh t tabel sebesar 1,98609 dan t hitung yang diperoleh sebesar 16,694. Dengan demikian maka nilai t hitung lebih besar dari pada nilai t tabel dimana 16,694 >1,98609 dan juga nilai signifikansi yang lebih kecil dari alpha $(0,000<0,005)$ ini berarti Ho ditolak dan Ha diterima dengan demikian dapat disimpulkan bahwa secara parsial terdapat pengaruh yang positif signifikan antara variabel curahan jam kerja $\left(\mathrm{X}_{1}\right)$ terhadap variabel pendapatan masyarakat (Y) di Kecamatan Insana Kabupaten TTU.

Berdasarkan hasil analisis deskriptif curahan jam kerja masyarakat dalam melakukan kegiatan usaha pertaniannya yang terendah adalah selama 12 jam/bulan yaitu $1,0 \%$ responden sedangkan yang tertinggi adalah mereka yang bekerja selama 65 jam per bulan 1,0\% responden dengan ratarata curahan jam kerja sebanyak 29,69 jam/bulan. Hal ini menunjukan bahwa curahan jam kerja masyarakat kita dalam mengupayakan peningkatan kesejahteraan masih tergolong rendah.. Masyarakat di Kecamatan Insana perlu lebih berusaha agar lebih banyak meluangkan waktu kerjanya agar searah dengan peningkatan produktivitas dan pendapatan. 


\section{2) Pengaruh Pendidikan $\left(\mathrm{X}_{2}\right)$ Terhadap Pendapatan ( $\left.\mathrm{Y}\right)$ Masyarakat Miskin Kecamatan Insana}

Berdasarkan penelitian diperoleh hasil terdapat pengaruh signifikan positif variabel pendidikan terhadap pendapatan rumah tangga miskin dengan nilai koefisien regresi pendidikan sebesar 21071,230 dan nilai $t_{\text {hitung }}$ sebesar 4,317 $>t_{\text {tabel }}$ sebesar 1,98609 sedangkan nilai signifikan $0,000<0,05$, berarti Ha diterima dan $\mathrm{H} 0$ ditolak dengan demikian dapat dikatakan bahwa terdapat pengaruh signifikan positif antara pendidikan $\left(\mathrm{X}_{2}\right)$ terhadap pendapatan $(\mathrm{Y})$ pada rumah tangga miskin di Kecamatan Insana Kabupaten Timor Tengah Utara.

Disisi lain hasil analisis deskriptif menunjukan bahwa tingkat pendidikan responden yang terendah yaitu setingkat Sekolah Dasar (0-6 Tahun) yaitu sebanyak 46 orang atau sebesar 47,9\% responden. Dengan rata-rata tingkat pendidikan sebesar 8,30 tahun duduk di bangku sekolah atau setingkat Sekolah Menengah Pertama Kelas 2. Angka ini menunjukan bahwa rta-rata responden yang bekerja di sektor pertanian dalam upaya memenuhi kebutuhan hidupnya tergolong rendah.

\section{3) Pengaruh Usia $\left(\mathbf{X}_{3}\right)$ Terhadap Pendapatan (Y) Masyarakat Miskin Kecamatan Insana.}

Berdasarkan penelitian diperoleh hasil terdapat pengaruh signifikan positif variabel usia terhadap pendapatan rumah tangga miskin dengan nilai koefisien regresi pendidikan sebesar 16807,292 dan nilai $t_{\text {hitung }}$ sebesar 2,772 $>t_{\text {tabel }}$ sebesar 1,98609 sedangkan nilai signifikan 0,002< 0,05, berarti Ha diterima dan $\mathrm{H} 0$ ditolak dengan demikian dapat dikatakan bahwa terdapat pengaruh signifikan positif antara usia $\left(\mathrm{X}_{3}\right)$ terhadap pendapatan $(\mathrm{Y})$ pada rumah tangga miskin di Kecamatan Insana Kabupaten Timor Tengah Utara.

Dari hasil analisis deskriptif diketahui bahwa rata-rata responden yang bekerja minimal adalah yang berusia 32 tahun atau sebesar $2,1 \%$ responden dan yang memiliki usia tertinggi adalah 71 tahun atau sebesar 1,0\% responden, sedangkan rata-rata usia yang bekerja sebesar 49,825 responden. Dari sisi usia sebenarnya mereka yang sementara bekerja ini cukup menunjukan usia yang tergolong produktif dalam melakukan kegiatan usaha dalam upaya meningkatkan pendapatan. Semakin tinggi usia kerja maka produktivitas makin tinggi sehingga berdampak pula pada peningkatan pendapatan.

\section{4) Pengaruh Jumlah Tanggungan Keluarga $\left(\mathrm{X}_{4}\right)$ Terhadap Pendapatan (Y) Masyarakat Miskin Kecamatan Insana}

Berdasarkan penelitian diperoleh hasil terdapat pengaruh signifikan positif variabel jumlah tanggungan keluarga terhadap pendapatan rumah tangga miskin dengan nilai koefisien regresi pendidikan sebesar 17024,149 dan nilai $t_{\text {hitung }}$ sebesar 3,413 $>t_{\text {tabel }}$ sebesar 1,98609 sedangkan nilai signifikan $0,000<0,05$, berarti Ha diterima dan $\mathrm{H} 0$ ditolak dengan demikian dapat dikatakan bahwa terdapat pengaruh positif signifikan antara jumlah tanggungan keluarga $\left(X_{3}\right)$ terhadap pendapatan (Y) pada rumah tangga miskin di Kecamatan Insana Kabupaten Timor Tengah Utara.

Hasil analisis deskriptif menunjukan bahwa jumlah tanggungan keluarga yang paling kecil adalah sebanyak 1 orang atau sebesar 4,2\% responden dan yang paling banyak adalah sebanyak 6 orang yaitu sebanyak 18 orang atau sebesar 18,8\% responden dengan rata-rata tanggungan sebesar 4,70. Hal ini juga menunjukan bahwa kehidupan masyarakat di Kecamatan Insana memiliki jumlah anggota keluarga yang cukup besar. Ada prinsip tradisional yang masih berlaku pada sebagian masyarakat pedesaan kitah bahwa "banyak anak banyak rejeki".

\section{KESIMPULAN}

Dari hasil analisis data, temuan lapangan dan pembahasan yang telah dijabarkan pada bab sebelumnya, maka adapun kesimpulan yang dapat diambil dari hasil penelitian ini antara lain adalah:

1) Ada pengaruh positif signifikan antara curahan jam kerja $\left(X_{1}\right)$ terhadap pendapatan $(Y)$ Masayarakat Miskin Kecamatan Insana Kabupaten Timor Tengah Utara. Hal ini dibuktikan dari nilai coeficient regresi sebesar 92412,585 dan nilai thitung yang lebih besar dari pada nilai t tabel atau 16,694 $>1,98609$ dan juga nilai signifikansi yang lebih kecil dari alpha $(0,000<0,005)$.

2) Ada pengaruh positif signifikan antara pendidikan $\left(\mathrm{X}_{2}\right)$ terhadap pendapatan $(\mathrm{Y})$ Masayarakat Miskin Kecamatan Insana Kabupaten Timor Tengah Utara. Hal ini dibuktikan dari nilai coeficient regresi 
sebesar 21071,230 dan nilai $t_{\text {hitung }}$ sebesar 4,317> $t_{\text {tabel }}$ sebesar 1,98609 dan juga nilai signifikansi yang lebih kecil dari alpha $(0,000<0,005)$.

3) Ada pengaruh positif signifikan antara usia $\left(X_{3}\right)$ terhadap pendapatan $(Y)$ Masayarakat Miskin Kecamatan Insana Kabupaten Timor Tengah Utara. Hal ini dibuktikan dari nilai coeficient regresi sebesar 16807,292 dan nilai $t_{\text {hitung }}$ sebesar 2,772 $>t_{\text {tabel }}$ sebesar 1,98609 dan juga nilai signifikansi yang lebih kecil dari alpha $(0,002<0,005)$.

4) Ada pengaruh positif signifikan antara jumlah tanggungan keluarga $\left(\mathrm{X}_{4}\right)$ terhadap pendapatan $(\mathrm{Y})$ Masayarakat Miskin Kecamatan Insana Kabupaten Timor Tengah Utara. Hal ini dibuktikan dari nilai coeficient regresi sebesar 17024,149 dan nilai $t_{\text {hitung }}$ sebesar 3,413> $t_{\text {tabel }}$ sebesar 1,98609 dan juga nilai signifikansi yang lebih kecil dari alpha $(0,000<0,005)$.

5) Secara simultan ada pengaruh yang signifikan antara variabel curahan jam kerja, pendidikan, usia dan jumlah tanggungan keluarga terhadap pendapatan masyarakat miskin di Kecamatan Insana Kabupaten Timor Tengah Utara. Hal ini dibuktikan dari nilai $F_{\text {hitung }} 253,195>$ nilai $F_{\text {tabel }} 2,47$ dan nilai signifikansi yang lebih kecil dari alpha $(0,000<0,005)$.

\section{DAFTAR PUSTAKA}

Amelia Risma. 2012 Analisis Faktor-Faktor Yang Mempengaruhi Kemiskinan Di Provinsi Nusa Tenggara Timur. Tesis Departemen Ilmu Ekonomi Fakultas Ekonomi Dan Manajemen Institut Pertanian Bogor.

Badan Pusat Statistik Kabupaten Timor Tengah Utara (TTU). 2016. Indikator Makro Sosial ekonomi. TTU

Bappeda, Kabupaten Timor Tengah Utara (TTU), 2017

Criswardani Suryawati, 2005. Memahami Kemiskinan Secara Multidimensional.

Djojohadikusumo, S. 1989. Ekonomi Pembangunan : Pengantar Ekonomi Pembangunan. Jakarta

Gujarati, Damodar. 1995. Ekonometrika Dasar. Jakarta : Erlangga

Harniati, U. 2002. Keunggulan dan Kelemahan Sistem Alley Cropping Serta Peluang dan Kendala Adopsinya Di Lahan Kering DAS Bagian Hulu. http://216.239.33.100/search?q:rudyct.tripod.com/sem1_023/umi_haryti.htm+lahan+kering\&hl.

Kuncoro, Mudjarat. 2000. Ekonomi Pembangunan. Yogyakarta : UPP-AMP.YKPN

Priyatno, 2013. Analisis Data Dengan Menggunakan SPSS 22.0. Erlangga Jakarta.

Riberu, J. 1993. Mengajar Dengan Sukses Petunjuk Untuk Merencanakan dan Menyampaikan Pengajaran. Jakarta : Gramedis

Sajogyo, Bunga Rampai Perekonomian Desa, (Jakarta: Yayasan Obor Indonesia,1982)

Sharp et al.. ( 2000), Economics of Social Issues 14th edition, New York: Irwin /McGraw-Hill

Simanjutak, P.J. 1998. Pengantar Ekonomi Sumber Daya Manusia. Jakarta : LPFE UI.

Singarimbun, M dan Sofyan, E. 1995 (Ed) Metode Penelitian Survey. Jakarta: Lembaga penelitian, pendidikan, penerangan ekonomi dan social.

Soegijoko, Budhy T. et al. 2001. "Pengelolaan Perkotaan dalam Menghadapi Tantangan Pembangunan Perkotaan”. Prosiding-Forum Manajemen Perkotaan, Bandung.

Suhardjo, A.J. 1997. Stratifikasi Kemiskinan dan Distribusi Pendapatan di Wilayah Pedesaan (Kasus Tiga Dusun Wilayah Karang Selatan, Gunung Merapi, Jawa Tengah). Majalah Geografi Indonesia No.

19 Th. 11, Maret 1997, Fakultas Geografi Universitas Gadjah Mada, Yogyakarta.

Sumardi. Suryabrata 1983. Psikologi Pendidikan. Jakarta :Rineka Cipta.

Sumarsono, dan Paina Partana. 2002. Sosiolinguistik. Yogyakarta: Sabda dan Pustaka pelajar. 
Sumarto, S. 2001. The Cronich Poor. The Transient Poor, and The Vulerability in Indonesia Before and After Crisis. SMERU Working Paper. Jakarta.

Supranto, J.2001. Ekonometrika. Jakarta: BPFE-UI

Tiza, Longai, 2014 Implementasi Program Pembangunan Desa Mandiri Anggaran Untuk Rakyat Menuju Sejahtera (Anggur Merah) (Studi di Badan Perencanaan Pembangunan Daerah Kabupaten Timor Tengah Utara. Wacana- Vol. 17, No. 2

Umar, H.2004. Metode Penelitian (untuk skripsi dan tesis bisnis). Jakarta: PT. Raja Grafindo Persada.

Wijanarko. Vendi, 2013, Faktor- Faktor Yang Mempengaruhi Kemiskinan Di Kecamatan Jelbuk

Kabupaten Jember, Skripsi. Ilmu Ekonomi Dan Studi Pembangunan Fakultas Ekonomi Universitas Jember

Wirosutarjo. 1996. Pengembangan Sumber Daya Manusia. Jakarta: Renieka Cipta.

Zainullah, Mochamad, 2015, Faktor-Faktor Yang Mempengaruhi Tingkat Kemiskinan Di Desa Tempurejo Kabupaten Jember, skripsi. Ilmu Ekonomi Studi Pembangunan Fakultas Ekonomi Universitas Jember. 